\title{
Single-shot lamina thoracic paravertebral block with ketofol for modified radical mastectomy
}

This article was published in the following Dove Press journal:

Local and Regional Anesthesia

6 October 2016

Number of times this article has been viewed

\author{
Ambrose Rukewe' \\ Oludolapo O Afuwape ${ }^{2}$ \\ Austin Ugheoke ${ }^{3}$ \\ Akinola A Fatiregun ${ }^{4}$ \\ 'Department of Anaesthesia \& \\ Critical Care, Faculty of Medicine, \\ University of Botswana, Gaborone, \\ Botswana; ${ }^{2}$ Department of Surgery, \\ College of Medicine ${ }^{3}$ Department \\ of Anaesthesia, University College \\ Hospital, Ibadan, ${ }^{4}$ World Health \\ Organisation, Akure, Ondo State, \\ Nigeria
}

\begin{abstract}
We describe the use of single-shot lamina thoracic paravertebral block (TPVB) with sedation for a 56-year-old female patient who had modified radical mastectomy with axillary clearance. Two years ago, she suffered vocal cord palsy post thyroidectomy, which was managed with tracheostomy. The tracheostomy tube was removed 8 months later, leaving the patient with persistent hoarseness of voice and left vocal cord palsy. She declined general anesthesia and consented for TPVB. The surgery lasted 95 minutes and was successfully completed with TPVB. Her vital signs were stable during the operation. She had low pain scores, minimal opioid use, early alimentation, and no postoperative nausea and vomiting and was discharged early. We present the anesthetic management of this case in our setting, where TPVB under ultrasound guidance and modern drug-delivery systems for sedation are unavailable.
\end{abstract}

Keywords: anesthesia, breast surgery, lamina, paravertebral, low resource

\section{Introduction}

Thoracic paravertebral block (TPVB) remains underutilized for breast cancer surgery in many low-resource centers despite its benefits such as prolonged analgesia, early ambulation and discharge, reduction in postoperative nausea and vomiting (PONV), and reduced cost of treatment. Its low level of acceptance may be due to safety concerns, as the potential for inadvertent vascular puncture, pneumothorax, and block failure exists. ${ }^{1-3}$ This risk is even greater with multiple thoracic-level injections. ${ }^{1,4,5}$ Very often, ultrasound, which allows real-time visualization during block placement with improved safety and success, is unavailable. In effect, general anesthesia (GA) remains the predominant anesthetic option for mastectomy. This is accompanied with the challenge of erratic supply of pain-relieving drugs in many sub-Saharan hospitals. ${ }^{6}$ Sometimes, GA may be contraindicated or undesirable, making the case for regional techniques in our practice environment. ${ }^{4}$ Our index patient had vocal cord palsy following thyroidectomy, which was managed with tracheostomy for 8 months, 2 years before presenting for modified radical mastectomy. The patient declined GA but consented to TPVB with sedation as an alternative. The surgeon communicated the patient's request via telephone since this anesthetist now based in Botswana was scheduled to visit the center as faculty for a Regional Anesthesia Workshop and the procedure was scheduled at the time of the Workshop. Our experience with singleshot lamina TPVB with ketofol is presented here for breast cancer surgery, in a setting where echo-guided approach and sophisticated drug-delivery systems are unavailable. The patient gave written informed consent for this publication.
Correspondence: Ambrose Rukewe Department of Anaesthesia \& Critical Care, Faculty of Medicine, University of Botswana, Private Bag 007/3,

Gaborone, Botswana

Tel +267 76226524

Email ambyrukewe@gmail.com 


\section{Case report}

A 56-year-old female patient, who weighed $66 \mathrm{~kg}$, was $158 \mathrm{~cm}$ tall and had American Society of Anesthesiologists' physical status I, was diagnosed with advanced right breast carcinoma. She presented 4 months prior to the surgery with a history of right breast lump; incisional biopsy revealed invasive ductal carcinoma. She was then commenced on neoadjuvant chemotherapy. Two years prior to this, she had total thyroidectomy under GA for simple multinodular goiter complicated with stridor, hypoxia, and hoarseness of voice, secondary to vocal cord palsy, which was managed with tracheostomy. The tracheostomy tube was removed 8 months later, leaving the patient with a persistent hoarseness of voice and defective left vocal cord. She was worked up for surgery after completion of neoadjuvant chemotherapy. Her serum biochemistry, hematology, electrocardiogram (ECG), and chest X-ray results were normal. She was instructed on the visual analog scale for pain intensity, where 0 meant no pain and 10 meant the worst pain imaginable. The anesthetic plan was explained to and discussed with the patient.

In the theater, intravenous (IV) access was established with $18 \mathrm{G}$ cannula on the left hand, and $500 \mathrm{~mL}$ normal saline solution was set up. Using the Classic-120 Multiparameter ${ }^{\circledR}$ monitor (Health-Care Equipment and Supplies Co. Ltd, Surrey, UK), noninvasive blood pressure (BP), pulse oximetry, and continuous ECG were monitored. Her baseline pulse rate was 83 beats/min (bpm), BP was $146 / 86 \mathrm{mmHg}$, and arterial oxygen saturation $\left(\mathrm{SaO}_{2}\right)$ was $98 \%$, breathing room air. Verbal contact was maintained throughout the block placement and surgery. With the patient sitting up on the operating table, a right-sided TPVB using Jüttner et al's ${ }^{1}$ modification of Pfeiffer et al's ${ }^{7}$ lamina technique was performed. The $\mathrm{C} 7-\mathrm{T} 6$ vertebral spinous processes were palpated and marked. Her T3 spinous process was identified using the scapular spine as a landmark, and $1.5 \mathrm{~cm}$ from the midline on the right side was marked as the needle entry point (Figure 1). Povidone iodine (10\%) solution was used for skin preparation, followed by infiltration of the injection site using $2 \mathrm{~mL} 1 \%$ lidocaine with 1:200,000 epinephrine. An 18 G Tuohy needle (Portex; Smiths Medical, Ashford, UK) was inserted and advanced in a paramedian sagittal plane at $45^{\circ}$ to the skin in the cranial direction until contact was made with the vertebral lamina at a depth of $4 \mathrm{~cm}$. With a negative test aspiration of air, blood, and cerebrospinal fluid, $6 \mathrm{~mL}$ 1\% lidocaine with 1:200,000 epinephrine was injected to facilitate insertion of the $20 \mathrm{G}$ epidural catheter (Portex) $3.0 \mathrm{~cm}$ beyond the needle tip into the paravertebral space. The catheter was secured, and the

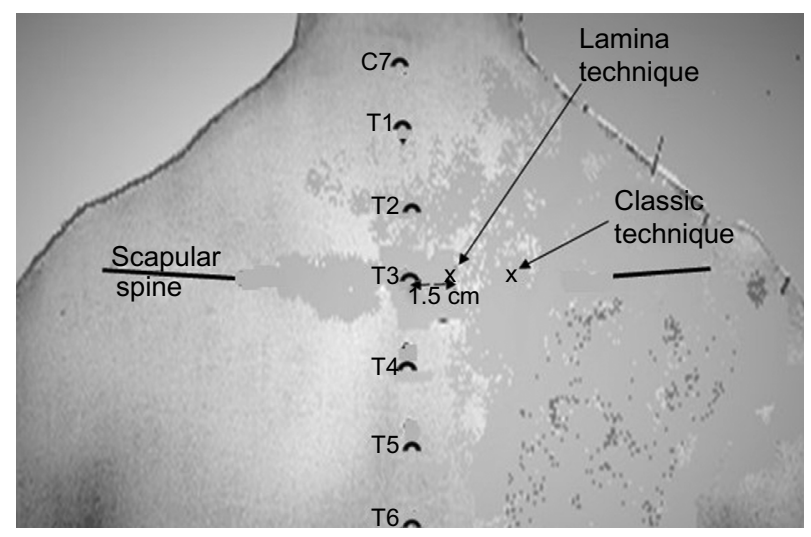

Figure I Illustration of the landmarks showing the scapular spine and C7-T6 spinous processes.

Notes: On the patient's right side, the lamina TPVB needle entry point is marked $1.5 \mathrm{~cm}$ lateral to the midline at the level of T3 spinous process. Tuohy needle is advanced in a strictly parasagittal plane at an angle of $45^{\circ}$ to the skin cranially to make contact with the lamina of $\mathrm{T} 3$ vertebra. The needle puncture site for the classic TPVB is more lateral, $\sim 3 \mathrm{~cm}$ from the midline.

Abbreviation: TPVB, thoracic paravertebral block.

patient was placed supine on the operating table. Test dose comprising $5 \mathrm{~mL} \mathrm{1 \%}$ lidocaine with 1:200,000 epinephrine was administered via the catheter while monitoring the patient's pulse rate, BP, respiration, and consciousness to exclude pneumothorax, epidural, or subarachnoid injection. Thereafter, $7 \mathrm{~mL} \mathrm{1 \%}$ lidocaine with 1:200,000 epinephrine and $20 \mathrm{~mL} 0.5 \%$ bupivacaine with 1:200,000 epinephrine were injected over 10 minutes. The block was completed within 28 minutes (catheter was removed after the local anesthetic [LA] injection) and was deemed adequate in 16 minutes by loss-of-cold and pinprick sensation (by the surgeon) over the operative area. The patient was observed to be shivering, but she was reassured and received IV fentanyl $50 \mu \mathrm{g}$ and midazolam $2 \mathrm{mg}$. Then a mixture of propofol $150 \mathrm{mg}$ and ketamine $100 \mathrm{mg}$ (ketofol) in $500 \mathrm{~mL}$ normal saline solution was infused at $2-4 \mathrm{~mL} / \mathrm{min}$ to achieve a Ramsey sedation score of 3-4. Supplemental oxygen at $4 \mathrm{~L} / \mathrm{min}$ via nasal prongs was commenced. The surgical incision was elliptical, which included the nipple-areolar complex and the underlying $14 \mathrm{~cm} \times 16 \mathrm{~cm}$ breast mass. The incision at the sternal border elicited pain, for which $10 \mathrm{~mL} 0.5 \%$ lidocaine with 1:200,000 epinephrine was infiltrated by the surgeon. Superior and inferior skin flaps were raised to the level of the clavicle and the lower coastal margins, respectively. The breast tissue was dissected off and the axilla was accessed through the same incision. The skin was closed over a drain. The duration of surgery was 95 minutes. A total of $245 \mathrm{~mL}$ ketofol was employed for conscious sedation. The blood loss was $150 \mathrm{~mL}$; intraoperative fluid administered was $500 \mathrm{~mL}$ normal saline and $500 \mathrm{~mL}$ 
Gelofusine. The patient's vital signs throughout surgery were as follows: pulse rate 60-82 bpm, BP 90/50-130/80 $\mathrm{mmHg}$, and $\mathrm{SaO}_{2} 100 \%$ at $4 \mathrm{~L} / \mathrm{min}$ oxygen via nasal prongs.

At the end of surgery, the patient was transferred awake to the recovery room, and IV paracetamol $600 \mathrm{mg}$ was administered. She was commenced on oral feeding 8 hours after surgery with good effect. On the ward in the first 24 hours, she had IV paracetamol $1 \mathrm{~g}$, IV pentazocine $30 \mathrm{mg}$, and oral Celebrex $200 \mathrm{mg}$; her pain score was $2-3$. In the next 24 hours, the pain score remained low; analgesics via oral route comprised Celebrex $400 \mathrm{mg}$ and paracetamol $3 \mathrm{~g}$ in divided doses. She was discharged home on the sixth day. Both the surgeon and patient described the anesthesia and pain control as satisfactory.

\section{Discussion}

We successfully employed single-shot lamina TPVB as an adjunct to $\mathrm{GA},{ }^{8}$ and this case report demonstrates that, combined with sedation, it can provide satisfactory operating conditions for patients who require a modified radical mastectomy. To the best of our knowledge, this is the first time TPVB was used as the sole anesthetic for mastectomy in our practice environment. Many authors have posited that regional anesthesia gives good intraoperative conditions and prolonged postoperative analgesia. ${ }^{2,4,5,9-11}$ Much of the literature agrees that regional anesthesia should be a key component of the surgical management of malignant breast disease because of superior perioperative pain relief despite reduced requirement of opioids, early ambulation, decreased incidence of chronic pain syndromes, and favorable immunomodulatory effects, and hence reduced tumor recurrence. ${ }^{12-16}$

This patient's anxiety about anesthesia was understandable; the vocal cord paralysis she suffered could have resulted from thyroidectomy and/or GA. Other relative contraindications to GA are comorbidities, cardiac or respiratory compromise, and advancing age. ${ }^{4,5,10,17}$ The patient's motivation for the block was remarkable, as there was no need for sedation prior to instituting TPVB, so she remained clearheaded, cooperative, and communicative. The good working relationship that existed between the surgeon and anesthetist allowed setting up the operation during the fifth University College Hospital, Ibadan, Regional Anesthesia Course when this anesthetist with experience in lamina TPVB was visiting that center as faculty.

Our ketofol (ketamine $100 \mathrm{mg}$ and propofol $150 \mathrm{mg}$ ) combination in $500 \mathrm{~mL}$ normal saline solution infused to achieve Ramsay sedation score 3-4 should be readily available in hospitals that cannot provide modern drug-delivery systems. Over the course of the surgery, which lasted 95 minutes, the total ketamine and propofol administered were 49 and $73.5 \mathrm{mg}$, respectively. With this combination, communication was maintained as much as possible, and the patient's vital signs were stable. There was no apnea, no emergence delirium, and no PONV. Low-dose ketamine employed in our ketofol combination is known to provide analgesia via inhibition of the $N$-methyl-d-aspartate receptor, interaction with the opioid, monoamine, and cholinergic receptor systems, as well as the anti-inflammatory effects via reduced cytokine production. ${ }^{18,19}$

Lack of expertise and safety concern in needling and local anesthetic dosing generally discourage the practice of nerve-blocking techniques in many hospitals in Nigeria. ${ }^{4,20}$ The lamina approach with a needle entry point at $1.5 \mathrm{~cm}$ lateral to the $\mathrm{T} 3$ spinous process using contact with the vertebra lamina as an end-point of insertion was developed by Pfeiffer et al. ${ }^{7}$ Our technique was described as a safer, highly effective, and easy-to-adopt modification compared to the classic landmark approach. ${ }^{1}$ The tunneling of the catheter into the paravertebral space engendered sufficient craniocaudal spread of LA, and our initial injection of $1 \%$ lidocaine with 1:200,000 epinephrine improved the onset time for surgery to begin 16 minutes after block completion, which is comparable with the incision time by Nikam et al. ${ }^{11}$ The appeal for lamina TPVB in settings such as ours is that a single injection of high LA volume with epinephrine to delay systemic absorption can reliably produce effective anesthesia and analgesia for mastectomies with axillary dissection. ${ }^{1,11}$ LA infiltration of the medial part of the breast occasioned by pain sensation during incision might be due to the insufficient time allowed for the block to take. Contralateral innervation of the breast has been identified as a possible reason for LA top-ups..$^{5,10}$

Shivering was the only side effect observed in our patient, and her discharge from the hospital after 6 days can be adjudged early given that patients' average hospital stay following mastectomies was 10 days from a previous study. ${ }^{21}$ The quality of anesthesia and analgesia was evident in low pain scores, minimal opioid use, and early alimentation.

\section{Conclusion}

Single-shot lamina TPVB with sedation was successfully used for a breast cancer surgery in a low-resource setting.

\section{Disclosure}

The authors report no conflicts of interest in this work. 


\section{References}

1. Jüttner T, Werdehausen R, Hermanns H, et al. The paravertebral lamina technique: a new regional anesthesia approach for breast surgery. J Clin Anesth. 2011;23(6):443-450.

2. Schnabel A, Reichl SU, Kranke P, Pogatzki-Zahn EM, Zahn PK. Efficacy and safety of paravertebral blocks in breast surgery: a meta-analysis of randomized controlled trials. Br J Anaesth. 2010;105(6):842-852.

3. Naja Z, Lönnqvist PA. Somatic paravertebral nerve blockade. Incidence of failed block and complications. Anaesthesia. 2001;56(12):1184-1188.

4. Kolawole IK, Adesina MD, Olaoye IO. Intercostal nerves block for mastectomy in two patients with advanced breast malignancy. J Natl Med Assoc. 2006;98(3):450-453.

5. Simpson J, Ariyarathenam A, Dunn J, Ford P. Breast surgery using thoracic paravertebral blockade and sedation alone. Anesthesiol Res Pract. 2014;2014:127467.

6. Harding R, Powell RA, Kiyange F, Downing J, Mwangi-Powell F. Provision of pain- and symptom-relieving drugs for HIV/AIDS in sub-Saharan Africa. J Pain Symptom Manage. 2010;40(3):405-415.

7. Pfeiffer G, Oppitz N, Schöne S, Richter-Heine I, Höhne M, Koltermann C. Analgesie der Achselhöhle durch Paravertebralkatheter in Laminatechnik [Analgesia of the axilla using a paravertebral catheter in the lamina technique]. Anaesthesist. 2006;55(4):423-427. German.

8. Rukewe A, Fatiregun A, Ademola AF, Ugheoke A. Single-shot lamina technique of paravertebral block as an adjunct to general anesthesia for modified radical mastectomy - a case report. Niger J Clin Pract. 2015; 18(3):429-431.

9. Klein SM, Bergh A, Steele SM, Georgiade GS, Greengrass RA. Thoracic paravertebral block for breast surgery. Anesth Analg. 2000;90(6): $1402-1405$

10. Terheggen MA, Wille F, Borel Rinkes IH, Ionescu TI, Knape JT. Paravertebral blockade for minor breast surgery. Anesth Analg. 2002;94(2):355-359.
11. Nikam S, Marghade P, Paliwal N, Lawhale S. Thoracic paravertebral block for breast surgery in a patient with ischemic heart disease. Anaesth Pain Intensive Care. 2014;18(3):280-281.

12. Kairaluoma PM, Bachmann MS, Rosenberg PH, Pere PJ. Preincisional paravertebral block reduces the prevalence of chronic pain after breast surgery. Anesth Analg. 2006;103(3):703-708.

13. Vila H Jr, Liu J, Kavasmaneck D. Paravertebral block: new benefits from an old procedure. Curr Opin Anaesthesiol. 2007;20(4): 316-318.

14. Exadaktylos AK, Buggy DJ, Moriarty DC, Mascha E, Sessler DI. Can anesthetic technique for primary breast cancer surgery affect recurrence or metastasis? Anesthesiology. 2006;105(4):660-664.

15. Sessler DI, Ben-Eliyahu S, Mascha EJ, Parat MO, Buggy DJ. Can regional analgesia reduce the risk of recurrence after breast cancer? Methodology of a multicenter randomized trial. Contemp Clin Trials. 2008;29(4):517-526.

16. Green JS, Tsui BC. Impact of anesthesia for cancer surgery: continuing professional development. Can J Anaesth. 2013;60(12): 1243-1269.

17. Kozanhan B, Basaran B, Kutlucan L, Ozmen S. Paravertebral block combined with sedation for a myasthenic patient undergoing breast augmentation. Case Rep Anesthesiol. 2015;2015:593282.

18. Hirota K, Lambert DG. Ketamine: new uses for an old drug? $\mathrm{Br} \mathrm{J}$ Anaesth. 2011;107(2):123-126.

19. De Kock M, Loix S, Lavand'homme P. Ketamine and peripheral inflammation. CNS Neurosci Ther. 2013;19(6):403-410.

20. Obasuyi BI, Alagbe-Briggs OT, Echem RC. Choice of anaesthesia for orthopaedic surgeries in a developing country: how appropriate? JMed Med Sci. 2013;4(3):101-106.

21. Ogundiran TO, Ayandipo OO, Ademola AF, Adebamowo CA. Mastectomy for management of breast cancer in Ibadan, Nigeria. BMC Surg. 2013;13:59.
Local and Regional Anesthesia

\section{Publish your work in this journal}

Local and Regional Anesthesia is an international, peer-reviewed, open access journal publishing on the development, pharmacology, delivery and targeting and clinical use of local and regional anesthetics and analgesics. The journal is included in PubMed, and welcomes submitted papers covering original research, basic science, clinical studies,

\section{Dovepress}

reviews and evaluations, guidelines, expert opinion and commentary, case reports and extended reports. The manuscript management system is completely online and includes a very quick and fair peer-review system, which is all easy to use. Visit http://www.dovepress.com/ testimonials.php to read real quotes from published authors. 